\title{
Maize Storage and Consumption Practices of Farmers in Handeni District, Tanzania: Corollaries for Mycotoxin Contamination
}

\author{
Ibrahim Shabani' ${ }^{1}$, Martin E. Kimanya ${ }^{2}$, Peter N. Gichuhi' ${ }^{1}$, Conrad Bonsi ${ }^{3}$, \\ Adelia C. Bovell-Benjamin ${ }^{*}$ \\ ${ }^{1}$ Department of Food and Nutritional Sciences, Tuskegee University, Tuskegee, USA \\ ${ }^{2}$ Department of Life Sciences and Bioengineering, Nelson Mandela African Institute of Science and Technology, \\ Arusha, Tanzania \\ ${ }^{3}$ Department of Agriculture, Tuskegee University, Tuskegee, USA \\ Email: acbenjamin@mytu.tuskegee.edu
}

Received 13 May 2015; accepted 4 August 2015; published 7 August 2015

Copyright (C) 2015 by authors and Scientific Research Publishing Inc.

This work is licensed under the Creative Commons Attribution International License (CC BY). http://creativecommons.org/licenses/by/4.0/

\section{Abstract}

In Tanzania, maize is the main complementary food for infants and primary school children. Dietary exposure to mycotoxins through complementary foods by Tanzanian infants is of concern. The maize storage and consumption practices of farmers in Handeni District, Tanzania and their implications for mycotoxin contamination of maize flour were investigated. A convenient sample of 60 farmers in Seza Kofi and Kwabojo villages in Mgambo and Ndolwa wards were surveyed. The majority of farmers $(95 \%)$ stored their maize in the house using the roofing and sack methods. Most farmers (67\%) did not visually or mechanically sort defective maize kernels before storage. In both villages, the most important storage problems reported by the farmers were rodents and insects. Forty two percent of the farmers surveyed indicated that they consumed dehulled maize, while 35 and $12 \%$ consumed non-dehulled and mixed (dehulled and non-dehulled), respectively. The preponderance of storage practices described was unfavorable to mycotoxin reduction in stored maize. It is therefore recommended that appropriate, area-specific farmer training regarding recommended storage practices including storage methods, effective management of storage pests and healthy maize preparation and consumption practices be conducted. Additionally, further research on maize storage and consumption practices for Tanzania is needed.

\section{Keywords}

Complementary Feeding, Aflatoxin, Fumonisin, Storage Practices, Maize Consumption Practices

\footnotetext{
${ }^{*}$ Corresponding author.
} 


\section{Introduction}

In the United Republic of Tanzania, maize is of fundamental importance both as a staple food and cash crop [1]. It is used primarily for direct human consumption [2]. Additionally, it is the main energy source in the diet accounting for $25 \%$ of total caloric intake, which is more than $75 \%$ of the cereal consumption in the country [2]. The annual per capita consumption of maize in Tanzania is estimated to be more than $115 \mathrm{~kg}$, and national consumption is projected to be three to four million metric tonnes per year [1]. Maize is consumed by the majority of households in both rural and urban Tanzania. Briefly, the maize grains are usually processed into flour and mixed with water to make porridge, which is the main complementary food for Tanzanian infants and primary school students in the school feeding program [2].

Maize production in Tanzania is associated with a wide range of constraints, including loss due to pests and diseases; decreased yields and contaminated grains due to a number of fungi and mycotoxins that can adversely affect human health. Mycotoxins have been detected in maize and maize-based foods in several parts of the world including Tanzania. Mycotoxins (including Fumonisins and Aflatoxins) enter the food chain through fungi growing on maize. They can be prevented by correct storage of the maize. During storage, maize can be contaminated with fungi. Mycotoxins can develop from Aspergillus flavus and Fusarium, common postharvest fungi in maize [3]. Infection and contamination of maize by mycotoxins are generally influenced by many factors including insect infestation and pre- and postharvest handling [4]. According to Fandohan et al. [4], harvested and stored maize grains in the tropical areas contain mycelium and spores of several fungal species such as Fusarium, Aspergillus and Penicillium that can come into contact, grow and compete for food in storage environments where the conditions are opportune. Maize storage practices have been reported to differ with agro-ecological areas [3].

Dietary exposure to mycotoxins through complementary foods by Tanzanian infants has been reported to be too high [5]. However, there is limited information on the storage practices and mycotoxin distribution in stored maize in the rural wards of Ndolwa and Mgambo in Handeni District, Tanzania. This study was part of a larger study with the overall objective of investigating the occurrence of toxigenic molds, and quantifying the presence and concentrations of selected mycotoxins in maize flour used for complementary feeding in Handeni District, Tanzania. Specifically, the maize storage and consumption practices of farmers in rural Handeni District (Seza Kofi and Kwebojo villages), and their implications for Aflatoxin and Fumonisin contamination of maize flour were investigated.

\section{Materials and Methods}

\subsection{Research Setting}

The study was conducted in the United Republic of Tanzania in the Tanga Region, Handeni District. Figure 1 and Figure 2 show a map of the study area and a schematic layout of the setting. Handeni District has an area of $7080 \mathrm{~km}^{2}$ and is located within the latitude 40 55' and 60 04'S and between longitudes 370 47' and $38046 \mathrm{E}$. The shared borders of Handeni District are shown in Figure 1. According to the Tanzania National Census, 2012, the population of Handeni District was 276,646. Most of the population is engaged in subsistence agriculture. The crops commonly grown include maize, cassava, beans, banana, sugarcane and various vegetables. All data related to village maize production and consumption patterns were tracked from the District Agricultural Officer, Handeni District. The District consists of seven Divisions and 20 wards. Of the 20 wards, two were selected (Mgambo and Ndolwa) based on the maize consumption patterns. One village was selected from each ward. A convenient sample of farmers from 30 households, which used maize flour in complementary feeding were obtained from each village by the Ward Executive Officer (WEO). Ndolwa ward, Seza Kofi village and Mgambo ward, Kwabojo village were selected.

\subsection{Study Design}

The study was conducted from October, 2013 to February 2015. A qualitative research design involving a cross-sectional interviewer administrated survey was survey was utilized. The survey instrument was a slightly modified version of that used by Hell et al. [3] in a similar study in Benin Republic. It was a 26-item questionnaire with some open-ended but predominantly closed questions. The questionnaire was divided into four sections: 1) demographics; 2) storage practices; 3) storage problems; and 4) maize consumption patterns. The 


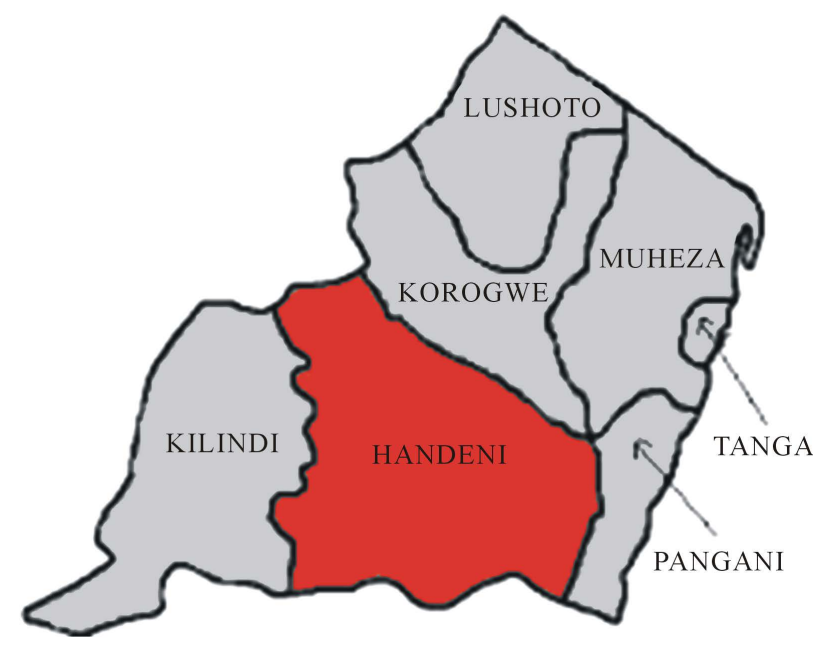

Figure 1. Map showing the study area of Handeni District, which is one of the eight districts of Tanga Region in Tanzania. Handeni is bordered to the west by the Kilindi District to the north by the Korogwe District, to the east by the Pangani District, and to the south by the Pwani Region.

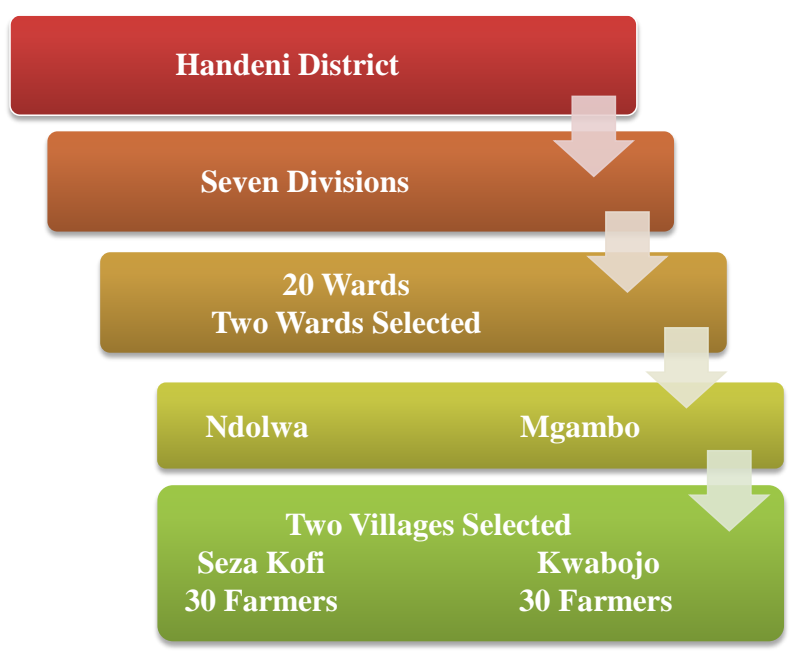

Figure 2. Schematic layout of the research setting, district, wards, villages and participants' selection.

surveys were conducted in the two villages with the Investigator administering the questionnaires.

\subsection{Data Analysis}

Descriptive statistics such as frequency counts, percentiles, means minimum and maximum values were used to describe the data collected.

\section{Results and Discussion}

\subsection{Demographic Characteristics and Maize Patterns}

A total of 60 farmers participated in the study. In Seza Kofi village, Ndolwa ward, $73 \%$ and $27 \%$ of the farmers were males and females, respectively. Similarly in Kwabojo village, Mgambo ward, $77 \%$ and $23 \%$ of the farmers were males and females, respectively. The majority (57\%) of farmers in Seza Kofi indicated that the maize 
variety they used was "Stucka". Other varieties mentioned were Travi, Mixed, Hybrid, Local, Star, Tan 250, TMU1. Four farmers (13\%) could not indicate which maize variety they used. In Kwabojo, $50 \%$ of the farmers reported using the "Local" variety. Of the farmers surveyed in Kwabojo, none mentioned using Stucka, Travi, Mixed or Hybrid variety. Overall, the two most popular varieties were "Stucka" and "Local". However, when both villages were combined, $63 \%$ of the farmers grew "Local" variety and $15 \%$ of the farmers did not know which variety they grew.

\subsection{Maize Storage}

Briefly, maize storage practices include two methods (roof and sack) observed in the current study. In the roof method, after harvesting the maize, the farmers store the maize in the ceiling for several months, utilizing it for cooking and/or selling during this period (Figure 3). In the sack method, farmers tend to shell the maize, and store the grains in polypropylene bags (Figure 3). The polypropylene bags are neither moisture nor insect resistant, thus causing the maize grains to be very susceptible to moisture and insect infestation. The insect infestation influences moisture increase, which could lead to mold growth and mycotoxin contamination. In response to the question "where do you store your maize"; $95 \%$ of the farmers responded in the house. In Seza Kofi and Kwabojo, $77 \%$ and $90 \%$ of the farmers, respectively, stored their maize for two months. Overall, the most common storage methods reported were roofing and sacks, with roofing dominating (55\% versus $43 \%$ ). However, in Kwobojo, both storage methods were equally used (Figure 4). Mboya et al. [6] studied the quality of maize stored using roof and sack storage methods in Katumba ward, Tanazania and concluded that both storage methods were inadequate for protecting maize against fungal infection.
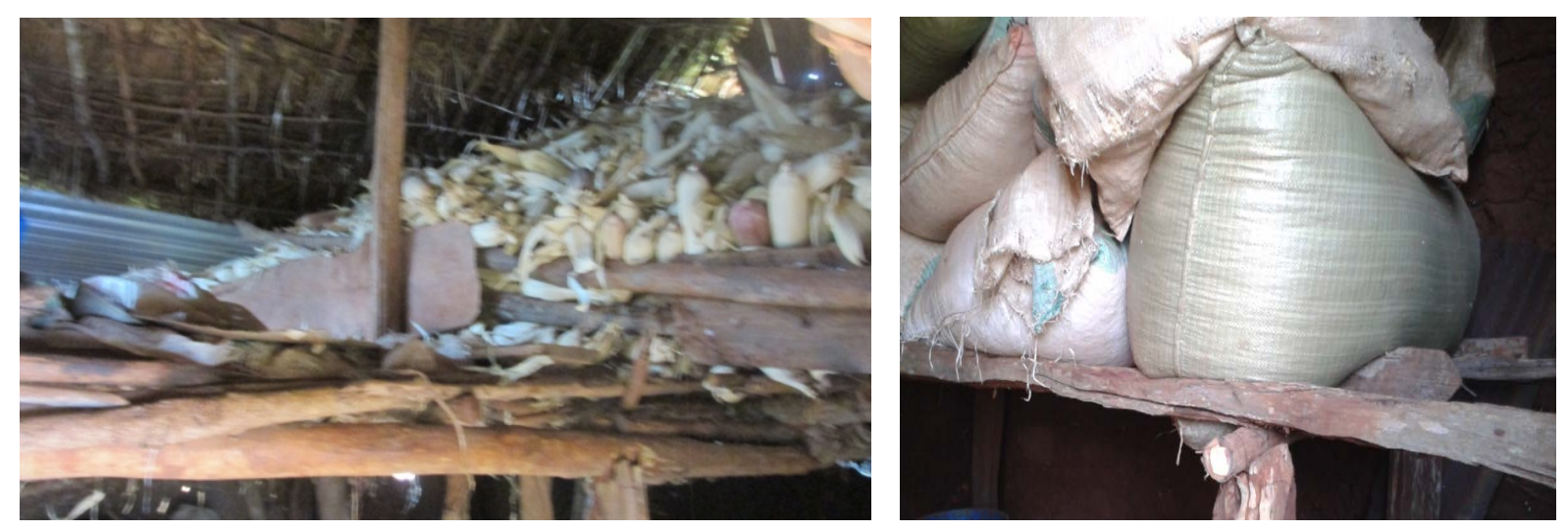

Figure 3. Left: Maize stored in the roof at Kwabojo village in Handeni District; right: Maize grains stored in sack (Polypropylene bags) at Seza Kofi village in Handeni District.

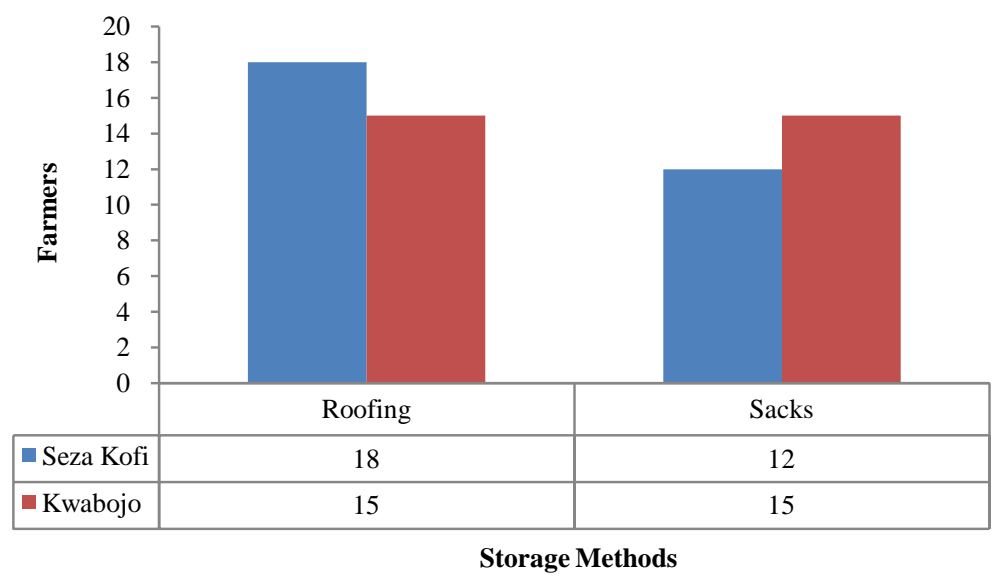

Figure 4. Maize storage methods used by farmers in Seza Kofi and Kwabojo villages, Tanzania. 


\subsection{Materials Used in Maize Storage}

The major materials used for constructing the stores were wood and clay (82\%). The majority (95\%) of the farmers did not give any explanation for their choice of materials. In Kwebojo, three farmers indicated that they used wood and clay for constructing their stores because it was simple and low cost. More than two-thirds of the farmers reported storing maize in their store every season. There was a range of responses when asked how many seasons they have used the stores. Answers ranged from 1 to more than 8 seasons; 23\%, $15 \%$ and 17\% of the farmers responded that they stored for 1,2 and more than 8 seasons, respectively. Seventy seven percent of the farmers indicated that they utilized their stores for maize only. Some farmers indicated that sunflower (Helianthus annuus) and cowpea (Vigna unguiculata) were the other commodities stored with the maize. Increased aflatoxin contamination has been observed in maize stored with cowpea; cowpea may become infected with $A$. flavus in the field.

\subsection{Maize Sorting Characteristics}

In this study $67 \%$ of the farmers did not visually or mechanically sort their defective maize kernel before storage (Figure 5). This is in contrast with Kimanya et al. [7] who found that a high 90\% of maize users in Tabora, Kilamanjaro and Irringa, Tanzania sorted their maize before use. Most mycotoxin contaminations occur on relatively few seeds, so separating damaged and discolored grains (sorting) can reduce toxin loads in stored maize [3] [8]. Pearson et al. [9] reported that in one pass through a commercial sorting machine for removing mycotoxin-contaminated white corn kernels, Aflatoxin and Fumonisin loads were reduced by $46 \%$ and $57 \%$, respectively. A second pass resulted in even more reductions. Riley and Norred [10] recommended removal of damaged maize and drying of kernels to the optimal moisture content before storage. Wicklow and Pearson [11] suggested that the removal of the contaminated kernels is a reasonable approach for reducing Aflatoxin or Fumonisin contamination.

\subsection{Maize Storage Problems}

In Seza Kofi and Kwabojo, the most important storage problems reported by the farmers were rodents (50\% of the farmers) an insects (40\% of the farmers). Farmers reported insects and rodents at various stages of the storage. Most of the farmers reported observing the problem at three intervals, that is: 1 ) at the beginning of the storage, $62 \%$ of the farmers; 2) after a few months of storage, $23 \%$ of farmers; and $25 \%$ of farmers at the end of the storage. Higher percentages of farmers in Seza Kofi reported both insect and rodent problems as compared with those in Kwabojo. The most common insects observed were maize weevils (Sitophilus zeamais), termites and Scania weevils. Scania weevil is the name commonly used for the Larger Grain Borer (LGB) or Prostephanus truncatus in Tanzania. More than $90 \%$ of the farmers indicated that they did not have any problems with molds in the season the study was conducted. However, $3 \%$ of the farmers in Kwabojo indicated problems with molds (Figure 6). In Benin, West Africa, more than $80 \%$ of farmers complained about storage problems, primarily insects and rodents as observed in the current study [3].

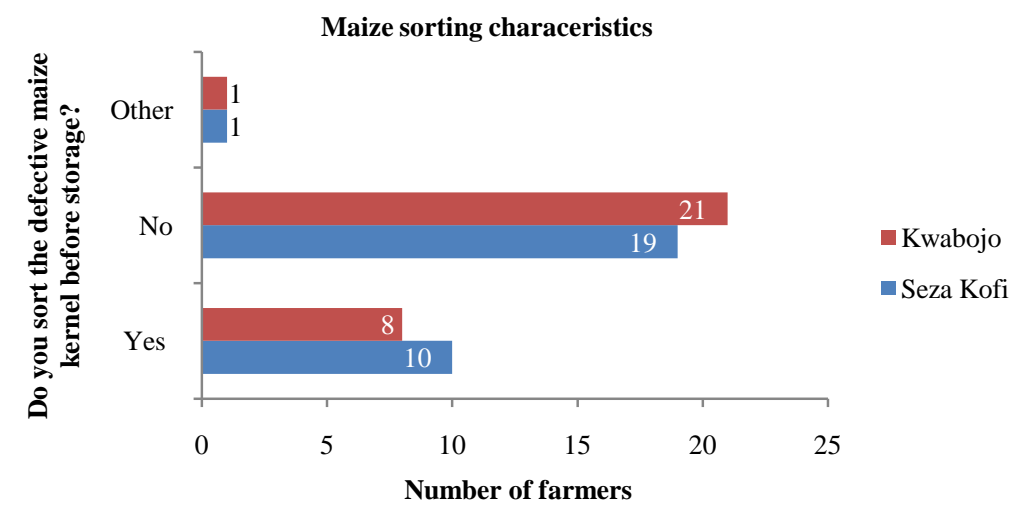

Figure 5. Farmers’ maize sorting characteristics in Seza Kofi and Kwabojo Villages, Tanzania. 
In this study, rodents and insects were the most serious pests of stored grains. Infestation results in weight loss, deterioration in quality and mold growth (http://www.new-ag.info). The impact of rodents on food availability and health is severe. It can be speculated here that the use of Rodenticides is not a feasible option for farmers in these villages because only $10 \%$ of the farmers indicated that they used it to resolve the rodent problem.

Rodenticides are usually expensive, not readily available, and likely to be dangerous if used incorrectly. Roughly $20 \%$ of the farmers reported using some type of insecticide to solve the problem. However, $57 \%$ of the farmers indicated that they did nothing to resolve the storage problem. This finding is consistent with that reported by Hell et al. [3], who found that 50\% of the farmers sampled in Benin, West Africa did nothing to counter storage problems. In this study, the farmers who did something to resolve the problem indicated using poison, fire/ash/smoke, Actellic ${ }^{\circledR}$ dust (pirimiphos-methyl) and Mverobarn. Lower aflatoxin level has been associated with the use of smoke or insecticide. More than half of the farmers indicated that they cleaned their store houses (60\%) and removed old grains (60\%) before stocking them with new maize. Therefore, $80 \%$ of the farmers did not see any maize germinate during storage. A small percentage of the farmers (12\%) did something else such as insecticide application, fire down or clean store houses before storage.

Farmers stored their maize as grains, in the husk, and dehusked, six farmers did not indicate the form in which their maize was stored (Figure 7). Overall, more farmers stored their maize in the husk than loose grains. It has been reported that good husk cover is a deterrent against insects and water infiltration [3]. Older studies have also reported lower aflatoxin levels in maize stored with good husk cover [12] [13]. More insect infestation and higher aflatoxin levels have been associated with maize stored as loose grains than those in the husk [14] [15].

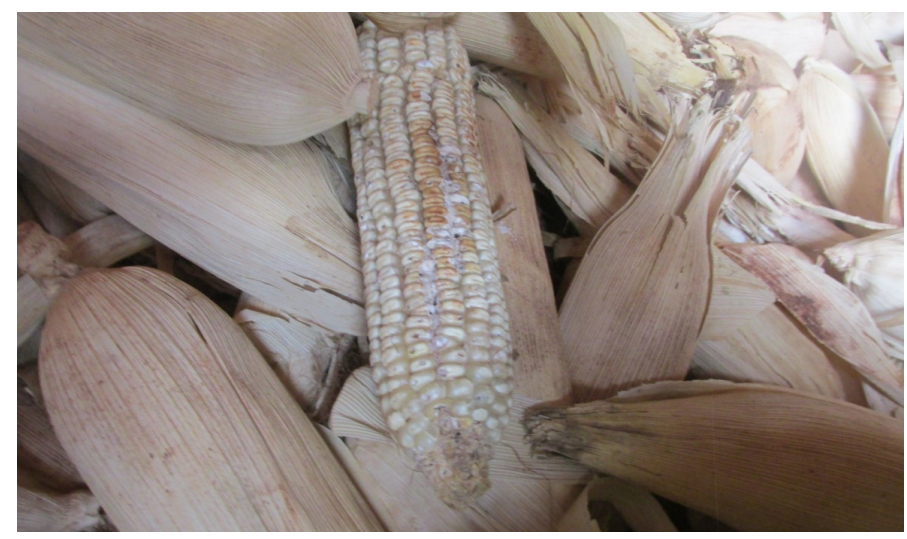

Figure 6. Observed insect infested maize with mold growth from farmers in Kwabojo village.

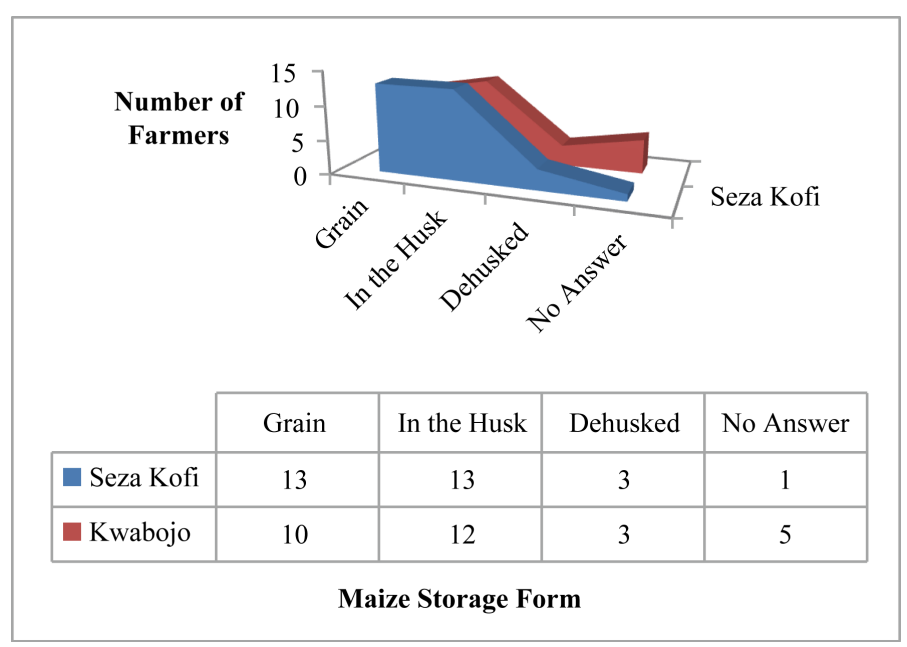

Figure 7. Maize storage forms as reported by farmers in Seza Kofi and Kwabojo Villages, Tanzania. 
Half of the farmers (50\%) reported not using pesticides during storage while $22 \%$ used, and $28 \%$ did not answer the question. Based on reports in the literature, it is important to know whether regulatory mechanisms are enforced for the use of pesticides by farmers in the Seza Kofi and Kwabojo. Ogah et al. [16] concluded that there was contamination of the food chain with residues of organochlorine pesticides in maize sold at markets in Nigeria; and some exceeded safety levels with probable detrimental consequences on human health.

\subsection{Maize Consumption Patterns}

Most of the farmers (42\%) surveyed indicated that they consumed dehulled maize while $35 \%$ and $12 \%$ consumed non-dehulled and mixed (dehulled and non-dehulled), respectively. These findings are higher than those reported by Kimanya et al. [7] who found that $30 \%$ of maize users surveyed in Tabora, Kilamanjaro and Irringa, Tanzania consumed non-dehulled maize. Dehulling is a milling technique that removes the outer layers of grain by abrasion. The layers removed in the dehulling process are those which are most susceptible to fungal attack and aflatoxin accumulation [17] [18]. Siwela et al. [19] found that there was a 92\% decrease in aflatoxin levels in dehulled maize meal compared with undehulled maize meal. The dehulling of maize grains either manually or mechanically before preparation of food was recommended by Siwela et al. [19]. In addition to removing aflatoxins from the outer layer of maize, dehulling removes phytate and reduces the lipid content of the seed, thus improving the storage quality [19] [20]. When asked what was done with the defective maize detected, 73\% of the farmers reported discarding it while the others said they consumed them or utilized as animal feed, mainly for chickens. Our findings were in contrast to those of Kimanya et al. [7] who reported that in Tabora, Kilamanjaro and Irringa, Tanzania, 53\% of the maize users in their study consumed the defective maize.

The findings from this study implied that farmers in Seza Kofi and Kwabojo have not yet fully grasped the importance of acceptable storage practices, and its relationship to mycotoxin contamination. For example, only a small number of farmers sorted their maize before storage, although it is known that post-harvest cleaning and sorting is the last line of defense to eliminate maize grains contaminated with mycotoxins [9]. Another instance is the type of storage method utilized by the farmers. The two main storage methods (roofing and sack) utilized by the farmers in this study are known to be ineffective against fungal infection in maize. If these messages were properly comprehended, maybe more efforts to sort maize before storage might be made. Furthermore, farmers would make more efforts to ensure protection from fungal infections for the maize stored in the roof and sacks.

Given the storage practices reported, the habitual use of maize flour as the main ingredient in complementary foods may expose children in Seza Kofi and Kwabojo villages to mycotoxin contamination. There is an urgent need to educate farmers in these villages about the relationships among acceptable storage practices, mycotoxin contamination, and public health impacts. Adequate rodent proofing is one of the most effective means of controlling rodents, which was a problem in these villages. However, most of the farmers in this study stored the maize within the household making it difficult to use rodent proofing.

\subsection{Study Limitation}

The study was cross-sectional during a single harvesting and storage period and the practices reported could vary during other harvesting and storage periods. The study was done on a small sample of farmers in two of 20 wards and a single village from each ward and this may not be representative, and cannot be generalized to Tanzanian or other groups of farmers.

\section{Conclusion}

Storage and consumption practices of maize used for complementary feeding were described. Maize flour is the major ingredient for complementary and traditional dishes throughout Tanzania. Dietary exposure to mycotoxins through complementary foods by Tanzanian infants has been reported to be too high [5]. Mycotoxins can adversely affect human health, and young Tanzanian children are at risk. Although some of the practices indicated by the farmers were conducive to curtailing mycotoxin infestation and contamination in stored maize, the majority of the storage practices described was unfavorable to mycotoxin reduction in their stored maize. It is therefore recommended that appropriate, area-specific farmer training regarding recommended storage practices including storage methods, effective management of storage pests and healthy maize preparation and consumption practices should be conducted. Additionally, the maize storage consumption patterns should be researched for 
the entire region and corrective programs and strategies put into place where necessary. Efforts should be directed not only to farmers, but also to consumers.

\section{Acknowledgements}

The authors wish to acknowledge the Innovative Agricultural Research Initiative (iAGRI) for the funding to conduct the research, Dr. Neema Kassim, Lecturer, School of Life Sciences and Bioegineering (LiSBE), NMAIST and Sylvester Gerald Temba, Senior Laboratory Scientist II, School of LiSBE, NM-AIST for their support and assistance with the research.

\section{References}

[1] Policy Brief (2010) Mitigating the Impact of Drought in Tanzania: The WEMA Intervention. http://www.aatf-africa.org/userfiles/WEMA-TZ-policy-brief1.pdf

[2] Barreiro-Hurle, J. (2012) Analysis of Incentives and Disincentives for Maize in the United Republic of Tanzania. Technical Notes Series, MAFAP, FAO, Rome.

[3] Hell, K., Fandohan, P., Bandyopadhyay, R., kiewick, S. Sikora, R. and Cotty, P.J. (2008) Pre- and Postharvest Management of Aflatoxin in Maize: An African Perspective. In: Leslie, J.F., Bandyopadhyay, R. and Visconti, A., Eds., Mycotoxins: Detection Methods, Management, Public Health and Agricultural Trade, Cromwell Press, Trowbridge, 219-230.

[4] Fandohan, P., Hell, K., Marasas, W.F.O. and Wingfield, M.J. (2003) Infection of Maize by Fusarium Species and Contamination with Fumonisin in Africa. African Journal of Biotechnology, 12, 570-579.

[5] Kimanya, E.M, De Meulenaer, B., Roberfroid, D., Lachat, C. and Kolsteren, P. (2010) Fumonisin Exposure through Maize in Complementary Foods Is Inversely Associated with Linear Growth of Infants in Tanzania. Molecular Nutrition \& Food Research, 54, 1659-1657. http://dx.doi.org/10.1002/mnfr.200900483

[6] Mboya, R., Tongoona, P., Yoo, K.S, Derera, J., Mudhara, M. and Langyintuo, A. (2011) The Quality of Maize Stored Using Roof and Sack Storage Methods in Katumba Ward, Rungwe District, Tanzania: Implications on Household Food Security. Journal of Stored Products and Postharvest Research, 2, 189-199.

[7] Kimanya, M., De Meulenaer, B., Bendantinguka, T., Ndomondo-Sigonda, M., Van Camp, J. and Kolsteren, P. (2008) Co-Occurrence of Fumonisins with Aflatoxins in Home Stored Maize for Human Consumption in Rural Villages of Tanzania. Food Additives \& Contaminants, 25, 1353-1364.

[8] Afolabi, C.G., Bandyopadhyay, R., Leslie, J.F. and Ekpo, E.J.A. (2006) Effect of Sorting on Incidence an Occurrence of Fumonisins and Fusarium verticillioides on Maize from Nigeria. Journal of Food Protection, 91, 279-286.

[9] Pearson, T.C., Wicklow, D.T. and Brabec, D.L. (2009) Characteristics and Sorting of White Food Corn Contaminated with Mycotoxins. Applied Engineering in Agriculture, 26, 109-113. http://dx.doi.org/10.13031/2013.29463

[10] Riley, R.T. and Norred, W.P. (1999) Mycotoxin Prevention and Decontamination-A Case Study on Maize. FNA/ANA, 23, 25-30.

[11] Wicklow, D.T. and Pearson, T.C. (2014) Detection and Removal of Single Mycotoxin Contaminated Maize Grains Following Harvest. 9th International Working Conference on Stored Product Protection, 15-18 October 2006, Campinas, 109-119. http://spiru.cgahr.ksu.edu/proj/iwcspp/pdf2/9/kps21.pdf

[12] Bilgrami, K.S., Ranjan, K.S. and Choudhary, A.K. (1991) Aflatoxin Contamination in Monocropping and Mixed Cropping Mustard Crops of Bihar. Indian Phytopathology, 44, 529-531.

[13] McMillian, W.W., Widstrom, N.W. and Wilson, D.M. (1987) Impact of Husk Type and Species of Infesting Insects on Aflatoxin Contamination in Preharvest Corn at Tifton, Georgia. Journal of Entomological Science, 22, 307-310.

[14] Wright, V.F. (1992) Assessment of Insect Infestation in Stored Maize and Their Relationship to Aspergiluus flavus Contamination. In: Semple, R.L. and Frio, A.S., Eds., Mycotoxin Prevention and Control in Food Grains, UNDP/FAO REGNET and ASEAN Grain Postharvest Programme, Bangkok, 110-116.

[15] Vowotor, K.A., Bosque-Perez, N.A. and Ayertey, J.N. (1995) Effect of Maize Variety and Storage form on the Development of Maize Weevil, Sitophilus zeamais Motschulsky. Journal of Stored Products Research, 31, 29-36. http://dx.doi.org/10.1016/0022-474X(94)00038-U

[16] Ogah, C.O., Coker, H.A. and Adepoju-Bello, A.A. (2011) Pesticide Residue Levels in Maize Samples from Markets in Lagos State, Nigeria. Nigerian Quarterly Journal of Hospital Medicine, 21, 169-174.

[17] Mienda, B.S. (2011) Preliminary Report of Dehulling Effect on the Occurrence and Distribution of Aspergillus flavus in Maize Grains Stored in Mubi Market. Advances in Applied Science Research, 2, 612-616.

Mutambuki, K. and Ngatia, C.M. (2008) Loss Assessment of On-Farm Stored Maize in Semi-Arid Area of Kitui Dis- 
trict, Kenya. 9th International Working Conference on Stored Product Protection, 15-18 October 2006, Campinas. http://spiru.cgahr.ksu.edu/proj/iwcspp/pdf2/9/kps21.pdf

[18] Payne, G.A. (1986) Aspergillus flavus Infection of Maize. In: Zuber, M.S., Lillehoj, E.B. and Renfro, B.L., Eds., Aflatoxin in Maize: Proceedings of the Workshop, CIMMYT, Mexico, 119-129.

[19] Siwela, A.H., Siwela, M., Matindi, G., Dube, S. and Nziramasanga, N. (2005) Decontamination of Aflatoxin-Contaminated Maize by Dehulling. Journal of the Science of Food and Agriculture, 85, 2535-2538. http://dx.doi.org/10.1002/jsfa.2288

[20] Hosney, R.C. (1994) Principles of Cereal Science and Technology. American Association of Cereal Chemists, St Paul, 21-24. 


\section{Appendix 1. Questionnaire (Adapted from [3])}

Date.

Name of participant (Optional).

District.

Ward.............................Village

Phone number. Gender. F......M.

\section{Storage Practices}

What is your maize variety....

Where do you store your maize? in the field For how many months do you store What storage method do you use? Roofing in the house

What construction materials did you used for constructing your store? Wood why?

Do you store maize in the store every season? No why? _ Y Yes

For how many seasons have you used the store

Do you use the same store for other products if yes list the products

Do you sort the defective kernels before storage?

\section{Storage Problems}

Do you have storage problems Yes__ No Which storage problem is the most important in the store. Insect

Molds others ? Rodents Birds

When did you observe this problem?

At the beginning

After few months

At the end of storage

What did you do to solve this problem list

Does the grain germinate in storage Yes

Do you clean the store house before storage

Do you remove old grains Yes

${ }_{\text {Yes__ }}{ }^{\text {No_ }}{ }_{\text {No_ }}$

What else did you do to clean the store before storage? ___ List

How did you store your maize: As grain

Did you use pesticides during storage? In the husk Dehusked other

\section{Food Use}

Do you consume Dehulled maize Non dehuled maize If defective maize detected, what use of the defective maize? Animal feed discarded clay_ metal and 